\title{
The Language Of Silence In The Therapeutic Setting Of Dental Medicine
}

\author{
Maria do Rosário Dias \\ Unidade de Investigação- \\ Centro de Investigação Multidisciplinar em Psicologia da Saúde Egas Moniz (CIMPSEM) \\ Egas Moniz - Cooperativa de Ensino Superior, \\ Monte de Caparica, Portugal. \\ Letícia Naben \\ Unidade de Investigação- \\ Centro de Investigação Multidisciplinar em Psicologia da Saúde Egas Moniz (CIMPSEM) \\ Egas Moniz - Cooperativa de Ensino Superior, \\ Monte de Caparica, Portugal.

Ana Ferreira
Unidade de Investigação-
Centro de Investigação Multidisciplinar em Psicologia da Saúde Egas Moniz (CIMPSEM)
Egas Moniz - Cooperativa de Ensino Superior,
Monte de Caparica, Portugal.
José João Mendes
Unidade de Investigação-
Centro de Investigação Multidisciplinar em Psicologia da Saúde Egas Moniz (CIMPSEM)
Egas Moniz - Cooperativa de Ensino Superior,
Monte de Caparica, Portugal.

ABSTRACT

The aim of the present study is to explore the perceptions associated with the nonverbal communication that is installed in the therapeutic setting of the practice of Dental Medicine, namely to: a) Determine the extent to which non-verbal signals are apprehended both by Dentists and Patients; b) Evaluate the perceptions of Dentists and Patients when exposed to the same non-verbal stimuli; C) Verify the existence of significant differences between Dentists and Patients in the capacity of apprehension of the signs. The results suggest that Patients do not seem to be aware of how they communicate their discomfort through non-verbal language. However, Dentists are aware that their adoption of a discomforting facial expression can condition the Patient's emotional state. Deepening the knowledge of non-verbal communication (NVC) allows Dentists to develop their communication skills, thus increasing the choice of the most appropriate intervention strategies in Dental Medicine Health Care.

Keywords: Perception of non-verbal language; Appointment setting in Dental Medicine; Psychometry; Language of Silence; Therapeutic setting.

\section{INTRODUCTION}

At present, health professionals at pre and postgraduate level should assume the role of Health Educators when faced with the challenge of preparing future doctors to join the practice of Medicine. This challenge requires a wide range of relational and pedagogical skills, in which 
the act of communicating with the Patient is understood not only as an immeasurable body of knowledge and technical skills, but also as a crucial collection of ethical and relational values, attitudes, intangible behaviours and relational styles that fall under the heading of a true "relational professionalism".

Becoming a Dentist requires not only technical skills and medical knowledge [1-2], but also patient care, namely the interaction with real individuals, to better understand their authentic needs. How do Health Educators convey these less tangible but important social skills?

Interpersonal communication is a key relational instrument for the quality of care provided by health professionals [3-6], insofar as it constitutes the basic support of all interactions carried out in the relationship with the Patient [5,7]. Mast (2007) refers apropos that suggestions made by the Patient may contain very important information for the doctor to decipher, both in diagnostic and treatment decisions [5]. In this way, health professionals should be able to decode and understand the messages that the Patient sends subliminally, as to establish an adequate care plan for the individual needs of the Patient. According to Roter et al. (2006), the non-verbal behaviours of this relational pair (doctor-Patient) are fundamental not only for the sedimentation of the therapeutic relationship, but also because of their influence in the therapeutic trajectory, particularly in the satisfaction, adherence and clinical outcomes of the care provided [6].

However, in order for this complex process to be effective, it is necessary to be aware of all non-verbal signals that are emitted by the Dentist-Patient pair and of the relational patterns that arise during their interaction [8]. Hence, it is necessary to accept relational communication as a dynamic process that involves the exchange of behaviour-influencing messages and which can be subdivided in two types: digital (verbal) communication, which refers to the words expressed through speech or writing, and analog (non-verbal) communication, which occurs through gestures, silences, voice tones, speech cadences, facial expressions or changes in body posture [9-11]. The non-verbal dimension of communication involves various manifestations of behaviours that are not expressed in words, and whose meaning depends on the situation or context in which they occur. Thus, we define by non-verbal behaviour all relational communication that do not include linguistic contents, such as facial expressions, smile, visual contact, head tilt, hand gestures, postural bases and paralinguistic speech (e.g. debit of speech, intensity, pauses, speech fluency, speech interruptions) $[6,12]$. These non-verbal cues can be used to complement, replace or contradict verbal communication, but also to demonstrate and subscribe feelings and emotions [13-14], since non-verbal communication complements and qualifies verbal language.

In fact, verbal language is either authenticated or paradoxically betrayed by non-verbal language, that is, by the tone of the voice and the way of employing words, through facial expressions and stares, by the body language that accompanies speech, by the use of physical distance between subjects (proxemia), by outfits and ornamental behaviour and also by expressed physical characteristics [15], as even silence may incorporate a symbolic meaning and have message value $[11,16]$.

The communication gaps and deficiencies of the Dentist-Patient pair found within many current dynamics of the relational and therapeutic process, imply a series of emerging risks, the greater of which may be considered the progressive impoverishment of the Doctor-Patient relationship. Unless otherwise taught, doctors may be unaware of the psychological conditionings of Patients that go beyond Physiology, thus reducing their human dimension into the symptomatic code of a mere clinical case. This ascendance of a predominantly naturalistic 
orientation of the Patient's body that is currently observed in Medical practice, risks alienating the body from the subject, transforming the human body into a metaphysical body, thus contracting Medical practice to a Metaphysics of the Body practice [17].

In this line of thought, humanizing the Medical act in hospital settings by means of therapeutic information provided to Patients proved ineffective [18], as the specialists' care production excess in the knowledge campus of Psychology and Behavioural Sciences. In fact, the DoctorPatient relationship is not merely a praxis, like listening to a heart with a stethoscope, but also an art, varying according to the unique characteristics and idiosyncrasies of the Doctor-Patient pair. Therefore, it is up to health professionals to develop communication skills that allow them to establish an adequate and effective relationship with Patients, facilitating a reliable clinical data collection and an adjusted perception of the Patient's problematic [9], hence promoting the satisfaction of Patient's health needs and overall well-being $[5-6,10]$. In fact, the relational and therapeutic communication between the Dentist-Patient pair influences the strategies of therapeutic adherence decisively and enhances greatly Patients' levels of satisfaction. As mentioned by Balint (1960), the medicine that the Doctor prescribes more often, is the Doctor himself as a person [20].

Thereby, the Dentist-Patient relationship should be conceived and lived as a therapeutic and pedagogical relationship, as a dual and singular encounter, to overcome the romanticism and good intentions that commonly preside over Doctor-Patient relationships [18-19]. The hyper complexity of therapeutic Dentist-Patient dyad advocates the adoption of relational model centred on the Patient (in a Patient-centric perspective), rather than in iatrogenic professional convictions of health care professionals or of health care institutions' functioning norms.

It is accepted by common sense that Patients are sensitive to several non-verbal behaviours emitted by Dentists, which can be interpreted in a positive or negative way $[4,6]$. However, these non-verbal cues, such as gestures, body position, clothing, and even the appointment setting, can be perceived and evaluated by Patients in a mostly varied way. In a study carried out by Mast (2007), the author points at behaviours such as looking at the Patient's eyes or the physical proximity of the Doctor as enablers of remarkable Patient satisfaction, suggesting that these variables seem to depend upon the personal characteristics of the doctor, namely of the nature of the gender [5]. Mast et al. (2008) also suggest that surgeons with a more dominant and haughty voice were more likely to be prosecuted for medical malpractice; these studies found that Patients with higher satisfaction revealed gender preferences - female doctors because of their more frequent gaze, more proxemia and softer voice [21]. In fact, in the faceto-face relationship that occurs in the therapeutic setting of Dental Medicine, non-verbal signals such as proxemia, kinetics, appearance and voice [27-29] acquire a peculiar communicational acuity. This is due, on one hand, to the invasive nature of the clinical act (further accentuated because the health professional is hidden behind a mask), and on the other hand, to the fact that Patients are impeded to speak, forcing the Dentist to manage and decode the signs of non-verbal communication emitted by the mute Patients through gestures, tone of voice and visual contact [30-31]. In addition, the gaze, together with facial expressions and associated micro expressions, seems to be embodied by Patients as the recondite speech of the mind, conveying emotions and the latent thoughts of the Patients in a subconscious way. However, there is no total linear correlation between speech and gestures in Patients, that is, gestures alone do not allow to decipher the intrapsychic reality of the individual. In fact, nonverbal language is often treacherous and refers to the most hidden places in the mind of the human being [32-33]. The gaze in the face-to-face communicational act is part of a game, whose rules range from sensed permission to look into each other's eyes, to divert them or to 
look aside, in which Patient and Doctor interact in a virtual space, enabling or not, an emotional atonement of this therapeutic dyad [34-38].

In order to know which non-verbal signals facilitate and which make appointments difficult, it is necessary to establish a benign relationship between Dentist and Patient, thus perfecting the communication capacities of this relational dyad [22-26]. The analysis of the particularities of non-verbal communication also seems to be crucial, since therapeutic adherence is totally dependent upon good relational communication between Doctor and Patient. Furthermore, the Doctor must also be able to communicate to the Patient in pedagogic terms, because it is with the empowerment conveyed by the education of the Patient that the real acceptance of his condition as a sick person emerges [18,39]. However, the literature review did not find studies that address the non-verbal communication of Patients in Dental Medicine appointment settings, based on a measurement instrument of psychometric nature, that could quantify objectively non-verbal behaviour, while at the same time detecting the richness of its meanings. Notwithstanding these methodological limitations, in recent years we have witnessed a proliferation of communication skills' programs aimed at improving the relational communication of the Dentist-Patient pair. However, despite robust empirical evidence of the importance of non-verbal communication embodied in the results of the therapeutic relationship, the study of non-verbal communication seems yet to be properly valued by health professionals.

In this article we intend to present a new line of research, focused on the non-verbal language emitted by the relational individual dyad Dentist-Patient, in Dental Medicine appointment settings. We considered that the facial expression of emotions is related to the subliminal narrative of emotions experienced by individuals. As such, concepts such as spatial behaviour, bodily contact, proxemia, posture, and gaze can be analysed as message codes of the "language of silence" that is established between Dentists and Patients in context of the therapeutic setting in Dental Medicine. To fully understand the paradox of facial expressions and Paralinguistics, we base our study approach in the concept of affective analgesia enunciated by Franklin (1998) [40]. In addition, we also intend to explore the non-verbal communication behaviours at the level of facial expressions, paralinguistic postures and body gestures, and the way in which the Dentist, in presence of a mute Patient during the clinical act, assumes the decoder role of the non-verbal language of the Patient.

Thus, it is necessary to invest in the interpretation of the signals emitted by Patients' gestures, to easy the discomfort usually associated with Dentist-Patient interactions, rooted in the excessive proxemia of the relational pair and the short therapeutic time devoted to the dialogue in dental appointments. In effect, the decoding of Patients' body gestures seems to be more valued by Dentists than by Patients, evidencing that the need to intervene in the "pair's relational communication ", for mutual increased relational experience.

In short, with the present exploratory study, we intend to create and implement a psychometric instrument as a means of evaluating the non-verbal communication emitted by Patients in dental appointments, therefore aiming at maximizing the success of intervention strategies in health care contexts.

\section{METHODS}

The present study is cross-sectional, of an exploratory nature, of quantitative type and with field intervention. 


\section{Participants}

A sample of convenience used to collect the data was composed by 184 Patients of both genders, aged over 18, recruited from the appointments of three selected institutions, namely a university clinic that provides services to the community and two public hospitals. The sample was also composed by 150 Dentists of both genders, who are active workers. In order to carry out the present study, the following criteria were defined for the sample composed by the Patients: i) Inclusion criteria - Age greater than 18 years old and to have gone to at least one dental appointment; ii) exclusion criterion: existence of cognitive, neurological or other deficit that impaired the ability to understand informed consent or the completion of the instruments to be used.

\section{Instrument}

\section{Construction of items}

The proposed instrument includes an evaluation scale of the perception of non-verbal behaviour in the appointment context, composed by a set of 34 statements for Patients, 29 statements for Dentists and a sociodemographic questionnaire. The Non-Verbal Language Scale (NVL) statements were elaborated based on the analysis of the existing literature on human communication and focusing non-verbal language, as well as on the empirical analysis of the appointment setting in Dental Medicine.

The instrument of evaluation of Non-Verbal Language Scale (NVL) was composed by a set of statements, which refer to Dentists and Patients impressions in the context of the appointment in Dental Medicine, classified in a scale of the Lickert type ("Always", "Almost Always", "Almost Never" and "Never") according the degree of agreement or disagreement with the proposed statements [41]. The instrument was composed by five categorical dimensions, defined as "Posture", "Look", "Facial Expression", "Gestures" and "Distances", both for Dentists and Patients, in order to analyse and compare equal thematic categories. Two distinct instrument versions were created, one for Dentists (composed by 29 statements and the other for Patients (composed by 34 statements). In order to understand the particularities of the participants included in the sample, a sociodemographic questionnaire was elaborated with questions identifying the general characteristics of the participants. The adopted questions are of the closed type, namely multiple questions and closed dichotomous answers.

The sociodemographic questionnaire for Patients included nine psychosocial questions defining the general characteristics of the sample subjects (such as gender, age, marital status, educational qualifications and household composition), as well as questions regarding the Patient's attendance at the Dental appointments, the extent of the treatments performed in the oral cavity, and the extent to which Patients believe to be able to evaluate the non-verbal signals present in the relational communication with other people. The sociodemographic questionnaire for Dentists included five psychosocial questions defining the general characteristics of the sample subjects (gender, age, marital status, educational qualifications of Dentists - pre-graduate student or postgraduate professional - and length of professional practice). An additional question intended to evaluate the extent to which Dentists believe to be able to evaluate the non-verbal signals present in the relational communication with Patients.

The statistical analysis of the data included the characterization of the sample under study, based on the descriptive analysis of all the variables. The statistical analysis was performed with the SPSS software, using the absolute and relative frequency calculations, after a first analysis of the consistency between the statements that make up the measurement instrument. 


\section{Focus group analysis}

The 34 statements were methodologically analysed in a focus group composed by two Psychologists, a Dentist and a Speech Therapist, in order to evaluate the pertinence of each one of the statements, regarding the non-verbal language construct approach applied to the context of the Dental Medicine appointments. To keep each statement on the scale, a criterion of agreement of $100 \%$ of the judges was considered decisive, that is, all the judges needed to be in agreement. In order to construct the measurement instrument, a content analysis of the statements was carried out in order to select those that optimized the metrological characteristics of the scale. The 34 statements were then maintained, after some adjustments regarding the phrasic construction and were arranged in a systematic manner by sections, with appropriate instructions for self-completion.

\section{Semantic analysis}

In order to verify if the proposed statements and the instructions presented were comprehensible, the instrument was applied in an initial sample of ten Patients and ten Dentists of the selected institutions. Each participant was asked to respond to the questionnaire and to point out possible difficulties, doubts or suggestions.

\section{Procedure}

It was necessary to require formal authorization from the institutions where the data was collected, ensuring all formalities were met regarding the anonymity and confidentiality of the data. The protocols were explained and distributed to the Dentists of the selected institutions, which completed them and asked their Patients for their self-completion, together with the signing of informed consent.

\section{Posture}

\section{RESULTS AND DISCUSSION}

Approximately 38\% of Patients report "Never" rigidly crossing their legs in the Dentist's chair when the therapeutic procedure bothers them. However, the Dentists have a different opinion, and 44\% claim that "Almost Always" happens. The rigidly crossing of Patients' legs can unconsciously denounce the fear of the unknown that the clinical procedure involves for Patients. In fact, muscular tension is one of the most common physical manifestations observed in Patients during the course of the therapeutic trajectory [42-44].

Regarding the level of relational interaction, 34\% of Patients "Never" consider uncomfortable the lack of interaction with the Dentist. On the contrary, Dentists diverge when considering the lack of such interaction uncomfortable: $30 \%$ of "Almost Always", against 34\% of "Almost Never".

\section{Look}

Not looking at the Patient is not considered by them as uncomfortable in $30 \%$ of the cases, while $36 \%$ of Dentists believe that this symbolic act may make the Patient feel uncomfortable. In addition, 53\% of Patients report that they "Never" consider being sparingly looked by the Dentists as a sign of disinterest, while 39\% of Dentists considers that not looking at Patients is "Almost Always" experienced as a sign of personal disinterest. This disparity of results denounces differences in the way gaze is interpreted by the relational pair. From the Dentist perspective, the look is important in establishing a relationship with the Patient, showing commitment and concern. However, from the Patient perspective, the act of not being looked at by the Dentist is not seen as lack of interest but rather as compensatory measure due to the excessive intimate distance between Doctor and Patient. Also, Patients seems to wish that Dentists focus their clinical look on the oral cavity rather than in themselves. Our findings 
contradict those of Oliveira and Gargantini (2003), according to whom the absence of the gaze is perceived by the Patients as a sign of dishonesty, anxiety and, in the context of Dental appointment, of disinterest [52]. According to our results, the Dentist-Patient interaction through the gaze, considered as an elected therapeutic instrument $[4-6,8,15]$, seems not yet to be properly valued by the relational pair as a therapeutic instrument.

Another disparity of results emerged in the "Look" category, this time regarding Patients' staring at frightening clinical instruments: 64\% of "Almost Always" referred to by Dentists, against 34\% of "Almost Never" and 31\% of "Never" referred to by Patients. This shows a discrepancy concerning the interpretation of the focus of Patients' eyes. Dentists report that this type of behaviour is very common, while Patients, paradoxically, deny it. Thus, staring at clinical instruments may constitute an unconscious defence operated by Patients, as a way of controlling their surroundings. In fact, about 51\% of Dentists affirm that Patients "Almost Never" close their eyes so they do not have to watch them work, nor see the clinical instruments that are being used. Nonetheless, 33\% of Patients report "Almost Never" having this behaviour. The fear of surgical instruments, properly documented in the scientific literature, is thus related to the fear of "real life" experience, triggered in the first place by high rotation clinical instruments [53] and secondly by the Dentist. In this sense, the Dentist himself serves as a vehicle for the sublimation of the experienced fear, since Patients tend to fear surgical instruments more than the medical intervention of Dentists [22]. In other words, when Patients close their eyes in order not to be confronted with the image of the instruments and /or the clinical acts performed, they sublime fear and anxiety, as if they could imaginatively block the anticipation of perceived pain. As the popular saying goes, "what the eyes do not see, the heart does not feel".

\section{Facial Expression}

Concerning facial expression, 34\% of Patients believed they "Never" feel uncomfortable when Dentists frowns, despite $31 \%$ of Dentists affirming that frowning makes Patients feel uncomfortable and distrustful "Almost Always". Nonetheless, regarding the contraction of the lips and eyebrows, 36\% of Patients consider that this type of gesture "Never" is uncomfortable, concordantly to 33\% of Dentists who "Almost Never" consider that Patient feels uncomfortable with this facial expression.

Due to the physical closeness between the Dentist-Patient pair, Patients tend not to look directly into Dentists' faces, so that they become unaware of their facial expressions. However, the results obtained by Dentists denounce them being aware that sometimes they exhibit a discomforting facial expression - such as frowning, which can symbolize doubt, fear or surprise - thus conditioning Patients' emotional state. Additionally, the contraction/tension of the lips can symbolize anxiety, nervousness and emotional preoccupation [54-55], although Dentists' mouths are often hidden by the use of a mask.

Not only exist non-verbal signs identified by Dentists that escape the perception of most Patients, but also behaviours expressed by Dentists that are not perceived by the clear majority of Patients. These discrepancies between the results obtained may be associated, on the one hand, to the functional asymmetry of the roles performed by Dentists and Patients [56], and on the other hand, to the phenomenon in which Patients, under manifest stress, unconsciously emit non-verbal signals.

In the context of the iatrogenesis caused by health professionals through the use of non-verbal language, Araújo et al. (2007), explained that Patients sovereignly choose non-verbal language so that health professionals can remain unaware of the injury induced in Patients. Thus, "if 
health professionals are unaware of the inadequacy of their own non-verbal signals, then they could hardly perceive and interpret the signs of anxiety, discontent, fear or doubt, caused by them and expressed by the Patient during their interaction" [3]. Furthermore, Mesquita (1997) demonstrated that professionals in the areas of Physical Education, Medicine and Psychology believe that knowledge, experience and the use of instruments relating to the observation and analysis of emotional states through both kinesis and the reading of the non-verbal signals, can enable health professionals to decode subjective emotional states, thus contributing to improve the efficiency and competence of health professionals as readers of their Patients' facial expressions [15].

\section{Gestures}

Most Patients (38\%) show a greater sense of control over the clinical act when they agree on a symbolic gesture with Dentists to stop if there is pain. According to these results, the great majority of Dentists (83\%) admit that they "Always" agree on a stop gesture with their Patients in case of pain. It is of vital importance the agreement of a gesture to stop the procedure in case of pain, to lessen Patients' anxiety levels in painful situations [45-46]. It should be noted that the feeling of lack of control is considered a risk factor for Patients' fears that may otherwise be directly conditioned [47-48]. This agreement between Patients and Dentists demonstrates the importance of non-verbal language for both in the therapeutic setting. In the impossibility of using oral expression, Patients 'gestures play a crucial role in the communication context of the relational pair.

Regarding the emission of alarm signals when they feel anxious/distressed, 50\% of Patients deny totally the emission of these signals, while $46 \%$ of Dentists report the occurrence of this phenomenon "Almost Always". The data suggest once again that Dentists are attentive to the postures and gestures of their Patients, denouncing on their part unequivocal interpersonal abilities to interpret the non-verbal signals emitted by Patients.

The literature accounts that signs of fear/anxiety can be identified through behaviour and the detection of more frequent physical signs, such as autosomal symptoms, tachycardia, sweating, tremor, flushing, gastrointestinal symptoms (e.g. abdominal noise or diarrhoea), headaches, shortness of breath, urinary urgency, pallor of the skin [49], shortness of breath, difficulty in concentrating (e.g. forgetting what to say when in the Dentist's chair), nervousness (e.g. shortness of voice when speaking or not knowing what to do with the hands in a dental appointment), irritability and difficulty in swallowing [22,50].

\section{Distances}

Approximately 67\% of Patients report "Never" leaving the Dentist's chair when they feel uncomfortable, although $43 \%$ of Dentists argue that this "Almost Always" occurs. Thus, the results suggest that Patients do not seem to be aware of how they communicate their discomfort through non-verbal language. However, Patient's body language is perceived by Dentist as a way of showing discomfort and insecurity. Simultaneously, this behaviour demonstrates the importance of proxemia, which conditions the Dentist-Patient relationship. Because an intimate distance is involved [51], body language acquires a crucial role in expressing the invasiveness felt in the body of Patients.

\section{CONCLUSION}

Research in facial expression in the context of non-verbal language has only been more profoundly addressed in the last two decades. In fact, the facial expression of emotions is associated to the subliminal communication of the unconscious narrative of the emotions experienced by the individual. As such, concepts such as spatial behaviour, body contact, 
interpersonal distance, posture and look signal the language of silence emitted by muted Patients and should therefore be included in the analysis of the empirical field of DentistPatients' relationship.

Thus, the multidisciplinary collaboration between Social and Behavioural Sciences and Biomedical Sciences is most urgent, since good sense knowledge must also be taught and thought through a pedagogically constructed reflection, not only in pre-graduate education, but also in the course of health professionals' careers, as a way to strengthen the therapeutic alliance. In the scope of future studies, it is considered pertinent the acquisition and development of personal skills Dentists in the field of relational communication, through the use of Dentist-Patient role plays, supervised by professionals of the Social and Behavioural Sciences. The video recording of these simulacra (case studies) using the role play technique further allows a critical analysis of the behaviours observed regarding the Dentist-Patient relationship.

In this sense, there is a need to evaluate or even to work on Patients' emotional development (e.g. stressful life events, accidents, traumatic events in childhood and adulthood, current emotions, how significant others respond to Patient's pain and emotions; how Patients experience or avoid various emotions, attitudes, and relationships) in the context of the DoctorPatient relationship. Similarly, it is necessary to invest in the interpretation of Patients' signals emitted by their body and by body gestures, which are often the only form of communication in the specific therapeutic setting of Dental Medicine, insofar as the space separating the Dentist from the Patient limits the communication, evidencing its non-verbal aspects. The decoding of non-verbal language seems to be more valued by Dentists than by Patients, evidencing that it is necessary to intervene in the "education of this therapeutic pair" so that the relational experience is mutual.

It should be noted that according to the preliminary results obtained in the present research, Dentists are essentially assumed as Patients' "readers of the facial expressions", in which the relationship established with the muted Patient becomes a sort of "therapeutic analgesia". It is therefore intended with the presentation of the preliminary results of this study, to contribute to the clarification and understanding of the non-verbal language aspects in the context of the Dentist-Patient relational communication, through the construction of an original measurement instrument.

We believe that further analysing the research object of this study can contribute not only to the empowerment of the communication skills of health professionals (pre and post-graduate), but also to the promotion of a higher level of Patients' adherence and satisfaction regarding the health care provided to them. For future research, we consider pertinent the acquisition and development of Dentists' personal skills in relational communication, using pedagogical simulacra in the context of Patients' appointments, supervised by Social and Behavioural Sciences' professionals. The video recording of simulacrums (case studies) in specific Curricular Units using the role play technique enables a later in loco critical analysis of verbal and non-verbal behaviours otherwise missed in the Dentist-Patient appointment. By sharing responsibilities, health professionals must collectively and proactively play a significant role as health promoters, modelling and reinforcing the "laic" meaning of behaviours, so that effective changes can be made in broader segments of the population. 
Dias, M. R., Naben, L., Ferreira, A., \& Mendes, J. J. (2018). The Language Of Silence In The Therapeutic Setting Of Dental Medicine. Advances in Social Sciences Research Journal, 5(12) 351-362.

\section{References}

Aldrich CK. The Medical Interview. New York: The Parthenon Publishing Group Inc. Amaral 1999.

Vianna LG, Vianna C, Bezerra AJ. Relação médico-paciente idoso: desafios e perspectivas. RBEM 2010;34(1):15059. http://dx.doi.org/10.1590/S0100-55022010000100018.

Araújo MT, Silva MJ, Puggina AC. A Comunicação não-verbal enquanto fator iatrogénico. Rev Esc Enferm USP 2007;41(3):419-25. http://dx.doi.org/10.1590/S008062342007000300011

Marcinowicz L, Konstantynowicz J, Godlewski C. Patients' perceptions of GP non-verbal communication: a qualitative study. BJGP 2010;60:83-7.

https://www.ncbi.nlm.nih.gov/pmc/articles/PMC2814260/pdf/bjgp60-083.pdf

Mast MS. On the importance of nonverbal communication in the physician-patient interaction. Patient Education and Counseling 2007;67:315-18. https://doi.org/10.1016/j.pec.2007.03.005

Roter DL, Frankel RM, Hall JA, et al. The Expression of Emotion Through Nonverbal Behaviour in Medical Visits Mechanisms and Outcomes. J Gen Inter Med 2006;21(Suppl 1):P28-P34.

https://www.ncbi.nlm.nih.gov/pmc/articles/PMC1484830/pdf/jgi_306.pdf

Pontes AC, Leitão IM, Ramos IC. Comunicação terapêutica em Enfermagem: instrumento essencial do cuidado. Rev Bras Enferm 2008;61(3):312-8. http://www.scielo.br/pdf/reben/v61n3/a06v61n3.pdf

Correia LM, Cardoso RM. “Comunicação não-verbal”. In Competências clínicas de comunicação, coordinated by RM Cardoso. Porto: Faculdade de Medicina UP 2012:143-55.

Machado AC, Brêtas AC. Comunicação não-verbal de idosos frente ao processo de dor. Rev Bras Enferm 2006;59(2):129-33. http://dx.doi.org/10.1590/S0034-71672006000200002

Machado MM, Leitão GC, Holanda FU. 0 conceito de ação comunicativa: Uma contribuição para a consulta de enfermagem. RLAE 2005;13(5):723-8. http://www.scielo.br/pdf/rlae/v13n5/v13n5a17.pdf

Watzlawick P, Beavin JH, Jackson DD. Pragmática da Comunicação Humana. São Paulo: Editora Cultrix 1967.

Silva PR. A comunicação na prática médica: seu papel como componente terapêutico. Revista Portuguesa de Clínica Geral 2008;24:505-12.

Ekman P. Emotions revealed, Recognizing Faces and Feelings to Improve Communication and Emotional Life. New York: ST. Martin's Griffin 2007.

Rossi-Barbosa LA, Lima CC, Queiroz IN, et al. A Percepção de Pacientes sobre a Comunicação não Verbal na Assistência Médica. RBEM 2010;34(3):363-70. http://dx.doi.org/10.1590/S0100-55022010000300005

Mesquita RM. Comunicação não-verbal: Relevância na atuação profissional. Revista Paulista de Educação Física 1997;11(2):155-63. http://citrus.uspnet.usp.br/eef/uploads/arquivo/v11\%20n2\%20artigo7.pdf

Nasio JD. O Silêncio Em Psicanálise. Campinas: Papirus 1989.

Dias C. Relação médico-doente ou introdução ao estudo da medicina de relação. Separata do «Jornal do Médico» C (1846) 1979:523-26.

Dias MR. A Esmeralda Perdida: A Informação Prestada ao Doente Oncológico. Lisboa: Climepsi Editores 2005.

Dias MR.“"Relação médico-doente: Que cumplicidade?”. In Clínica Dentária Integrada: Contributos Bio-psico-sociais, edited by MR Dias and A Amorim. Monte de Caparica: Egas Moniz Publicações 2002:53-61.

Balint M. Le Médecin, son malade et la maladie. Paris: PUF 1960.

Mast MS, Hall JA, Klöckner C, et al. Physician Gender Affects How Physician Nonverbal Behavior Is Related to Patient Satisfaction. Medical Care 2008;46(12):1212-18.

Amorim VC. O Medo e a Ansiedade em Odontologia. Rev Odontol Univ São Paulo 1992;19(2):11-2.

Banaco RA. 0 Impacto do Atendimento sobre a Pessoa do Terapeuta. Temas em Psicologia 1993;1(2):71-9. http://pepsic.bvsalud.org/pdf/tp/v1n2/v1n2a10.pdf

Carvalho Teixeira JA. "Comunicação em saúde: Relação técnicos de saúde-utentes". Análise Psicológica 2004;22(3):615-20.

Lustosa MA, Alcaires J, Costa JC. Adesão do paciente ao tratamento no hospital geral. Revista da SBPH 2001;14(2):27-49. http://pepsic.bvsalud.org/pdf/rsbph/v14n2/v14n2a04.pdf 
Salgado R. 0 que facilita e o que dificulta uma consulta. Revista Portuguesa de Clínica Geral 2008;24:513-8. http://dx.doi.org/10.32385/rpmgf.v24i4.10532

Birdwhistell RL. Kinesics and context: Essays on body motion communication. Philadelphia: University of Pennsylvania Press 1970.

De Ruiter JP. Postcards from the mind: The relationship between speech, imagistic gesture, and thought. Gesture 2007;7(1):21-38.

Goldin-Meadow S. Gestures role in the learning process. Theory into Practice 2004;43:314-21.

Sikorski W. Paralinguistic communication in the therapeutic relationship. Archives of Psychiatry and Psycotherapy 2012;1:49-54. http://archivespp.pl/uploads/images/2012_14_1/Sikorski49_APP1_2012.pdf

Vidigal MJ. 0 silêncio na teoria e na prática psicanalitica. Revista Portuguesa de Psicanálise 1992;11:22-8.

Davis F. A comunicação não-verbal. São Paulo: Summus 1979.

Schelles S. A importância da linguagem não-verbal nas relações de liderança nas organizações. Revista Esfera 2008;1:1-8.

Cohen-Cole SA. The Medical Interview: The Three-Function Approach. St. Louis, MO: Mosby Year Book Inc 1991.

Mayer JD, Salovey P, Caruso DR, et al. Measuring emotional intelligence with the MSCEIT V2.0. Emotion 2003;3:87105. http://dx.doi.org/10.1037/1528-3542.3.1.97

Matthews G, Zeidner M, Roberts RD. Emotional Intelligence: Science \& Myth. Cambridge, MA: MIT Press 2002.

Novack DH. Therapeutic aspects of the clinical encounter. J Gen Inter Med 1987;2:347-54.

Teixeira JM. A relação médico-doente: da fisiologia à fenomologia. Saúde Mental 2002;4(3):5-8. https://repositorio-aberto.up.pt/bitstream/10216/6885/2/83522.pdf

Taylor KM. "Telling bad news": physicians and the disclosure of undesirable information. Sociology of Health \& Illness 1998;10(2):109-32. https://doi.org/10.1111/1467-9566.ep11340733

Franklin KB. Analgesia and Abuse Potential: An Accidental Association or a Common Substrate?. Pharmacology Biochemistry and Behavior 1998;59(4):993-1002. https://doi.org/10.1016/S0091-3057(97)00535-2

Fortin MF. O Processo de Investigação. Lisboa: Lusociência - Edições Técnicas e Científicas 1999.

Góes MP, Domingues MC, Couto GB, et al. Anxiety, fear and vital signs of the child signs of the child patients. Odontologia Clínico-Científica 2010;9(1):39-44.

Possobon RF, Carrascoza KC, Moraes ABA, et al. 0 tratamento Odontológico como Gerador de Ansiedade. Psicologia em Estudo 2007;12(3):609-16. http://www.scielo.br/pdf/pe/v12n3/v12n3a18

Reis PE, Gomes IP, Fonseca CM, et al. Reflexões Acerca da Comunicação Enquanto Facilitadora da Humanização Da Assistência em Saúde. Revista Eletrônica de Enfermagem do UNIEURO 2009;2(1):81-92.

Frias-Bulhosa J. Stress em Medicina Dentária. Revista de Saúde Oral 1996;2:126-34.

Petry PC, Toassi RF, Scota AC, et al. Ansiedade do paciente idoso frente ao tratamento odontológico. Revista Gaúcha de Odontologia 2006;54:191-4.

Logan HL, Baron RS, Keeley K, et al. Desired control and felt control as mediators of stress in a dental setting. Health Psychology 1991;10(5):352-9.

Singh KA, Moraes AB, Ambrosano GM. Fear, anxiety and control related to dental treatment. Pesquisa Odontológica Brasileira 2000;14(2):131-6. http://dx.doi.org/10.1590/S1517-74912000000200007

Colares V, Caraciolo GM, Miranda AM, et al. Medo e/ou Ansiedade como Fator Inibitório para a Visita ao Dentista. Arquivos em Odontologia 2004;40(1),59-72.

https://www.odonto.ufmg.br/revista/wp-content/uploads/sites/10/2016/06/AEO-v40-n1-arch4-2004.pdf

Barreto RC, Pereira GA. Farmacoterapia na clínica Odontológica. Paraíba: Editora Universitária (UFPB) 2008.

Hall E. A Dimensão Oculta. Lisboa: Relógio d'Agua 1986.

Oliveira MH, Gargantini MB. Comunicação e Gagueira. Estudos de Psicologia 2003;20(1):51-60.

http://dx.doi.org/10.1590/S0103-166X2003000100005

Costa RSM, Ribeiro SN, Cabra ED. Fatores determinantes de experiência dolorosa durante atendimento odontológico. Revista da Dor. São Paulo 2012;13(4):365-70. http://www.scielo.br/pdf/rdor/v13n4/11.pdf 
Dias, M. R., Naben, L., Ferreira, A., \& Mendes, J. J. (2018). The Language Of Silence In The Therapeutic Setting Of Dental Medicine. Advances in Social Sciences Research Journal, 5(12) 351-362.

Silva MJ. 0 papel da comunicação na humanização da atenção à saúde. Revista Bioética 2002a;10(2):73-88. http://revistabioetica.cfm.org.br/index.php/revista_bioetica/article/view/215/216

Silva MJ. Comunicação tem remédio: A comunicação nas relações interpessoais em saúde. São Paulo: Edições Loyola 2002b.

Caprara A, Rodrigues J. A relação assimétrica médico-paciente: repensando o vínculo terapêutico. Ciências \& Saúde Coletiva 2004;9(1):139-146. http://dx.doi.org/10.1590/S1413-81232004000100014

Corraze J. As Comunicações Não-Verbais. Rio de Janeiro: Zahar 1982. 